\title{
The effect of introversion and Extroverts of individuals in the socialization of public space
}

\author{
Zohre Yadegari \\ University of Kashan, Iran \\ zo_yadegari@yahoo.com \\ Behnoud Alinaghi \\ arc.behnoud.alinaghi@gmail.com
}

\begin{abstract}
Urban architects and designers have been trying to create life in the public space for many years. One way to make space dynamic is to consider socialization. Public space requires socialization and require people to be present in the environment. This study identifies the way to socialization by creating a sense of belonging in space, by exploring a sense of belonging in space; he improve the quality of public space. It expresses a sense of belonging to individual needs such as introverted and extroverted traits. This research starts its work by basic question that they are looking in public space. The purpose of this study is to investigate the concepts of introversion and extroversion as factors affecting the quality of public space. After reviewing these studies, criteria and principles for the socialization of public spaces are outlined. The results of the authors' studies showed that to create a space for personality needs, one should have space with approaches such as: Space for energy depletion, space, diversity in the environment and high quality of space for long-term use. Space tranquility for group activities are also essential. And for designers who value the perpetuation of identity and, these components offer design solutions.
\end{abstract}

Keywords. Introversion and Extroversion; Sociability; Public space; Sense of belonging

\section{Introduction}

In the contemporary era, with the development and growth of cities, paying attention to the "central neighborhood" and "citizen participation" was crucial to the management and administration of the city. Nowadays, human components are very important in urban design(Gehl \& Gemzøe, 2004). One of the most important strategies in revitalizing cities is "social development and attention" to urban space.(Thomson \& Etienne, 2017) Therefore, attention to human components is important and needs to be studied in different sectors. One of the most important pillars of the city is public space, which always has a quality and dynamic public space.

Public spaces in the city are used by people for cultural and social activities(Golany \& Ojima, 1996). If the urban space is suitable for the city, it can provide new activities in addition to responding to the needs of ordinary citizens. These activities are shaped by people's interests as well as community culture (Gehl, 2011). 
Public space always requires the presence of individuals, and if it does not lead to social interactions, it cannot be considered public space (Tibbalds, 1992). Therefore, socialization and social interaction have a fundamental and effective meaning in the public space. The process of socialization can be achieved by establishing interactions and social interactions between individuals in public spaces or shared architectural spaces, the ability to participate effectively in interaction with others, both in private and in public professional life, is crucial(Forgas \& Jones, 2000). As a result, paying attention to social relationships is effective on the quality of public space.

One way to achieve social interaction in space is to feel sense of belonging. Therefore, social relationships create a sense of belonging to the place. This feeling helps to make the space sociable. This socialization in society also contributes to the individual development of human. As a result, when a space is created exclusively for social interaction, it reinforces social relationships and creates a sense of belonging in the same space (Carmona, Heath, Oc, \& Tiesdell, 2012) A sense of belonging in space as mentioned above is a need for social relationships in space that create a sense of belonging with a social relationship. To achieve this concept, one needs to consider the needs and personality factors of individuals. Because attention to these two components causes social behaviors that create a sense of belonging in space and empower to strengthen relationships between individuals and space (Pakzad, 2010).

To respond to the needs and to identify personality factors, we examine the concepts of introversion and extroversion. Factors such as "personality and individual behavior make a person psychologically unique"(Namazian \& Mehdipour, 2013). These differences can be attributed to personal differences and how they relate to the environment. For example, an introvert takes more personal space than an extrovert and spends more time bouncing off his invisible bubble. Similarly, those who are prone to anxiety are more likely to distance themselves and others(Altman, 1975).Therefore, it is important to pay attention to the properties of introverts and extroverts. That creates a space that fits in with these concepts helps to raise a sense of belonging.

This study investigates personality components that are perceived as factors in emotion perception. Accordingly, it will first examine the sociable public space and then introduce personality components.

\section{Objectives of the research}

This study examines the impact of personality traits in space, relying on psychology knowledge and socialization analysis in the public space. Also, by understanding the concepts of introversion and extroversion, it examines the factors that influence the quality of public space.

\section{Research Questions \\ * what are the needs of introverts and extroverts in the public space? ** What role does personality play in creating a sense of belonging? *** How do personality factors influence the quality of public space?}

\section{Research Method}

This research is a qualitative research. In this research, data collection was done in three areas of architecture, environmental psychology and library psychology by library studies method. In addition, by analyzing the data logically, we attempted to refine the parameters affecting the quality of urban space in creating a sense of belonging and dynamics of urban space according to different personality types. 
In this section, a logical analysis of the influential aspects of each domain is presented in the form of keywords in the form of tables. Finally, the data extracted from these areas, or abstract tables of studies, are compared with the comparative method, and the design patterns in the architectural space are extracted to suit each personality type. Obtained solutions are Provided In the form of suggestions In Conclusions section.

\section{Background Check}

In contemporary psychology, environmental psychology has been extensively studied in architecture, and the concepts of socialization and its effects in the public space have been studied by many researchers. Public Space Research by researchers such as Madani Pour in the Public and Private Space Book of the City, Bentley et al. Analyze the factors affecting urban space. In addition, scholars such as Lawson, Lang, Carmona and individuals such as Behzad Far, Bahraini, and Rafi'i have analyzed the public space in their research. In 1959, for the first time, Azmund introduced the concept of socialization. Ian Gol is one of the scholars who has greatly influenced the concept of man and the environment. Putnam (1998) Tibalds (1992) Lang (2000) addressed the role of society in urban space. In his book Social Psychology of Interaction: Interpersonal Behavior, Fergas explores human components in the public sphere. It can also be acknowledged that money (Pol) in 2002 was a component of the sense of belonging in urban space. In addition, Pakzad has always investigated the sense of belonging and needs in architectural spaces in his research. In his book Inspiration in the Environment, Shah Choraghi, in addition to his sense of belonging and socialization in the public space, also expressed personality components. Namazian and Mehdi Pour have explored the role of introversion and extroversion in personal space in their research. It has also been extensively analyzed and analyzed in the psychology of human concepts. Researchers such as Raas, Shultz, Karimi have described personality concepts. Pervin and Jon have also analyzed the psychological dimension of the human personality in his book Personality: Theory and Research.

\section{Theoretical Basics}

In this study, the authors, recognizing the importance of socialization in the public space, investigated the component of sense of belonging in the architectural space. For experts, the sense of belonging in the environment is one of the most important pillars of socialization. On the other hand, the sense of belonging to one's individuality and human needs is important.

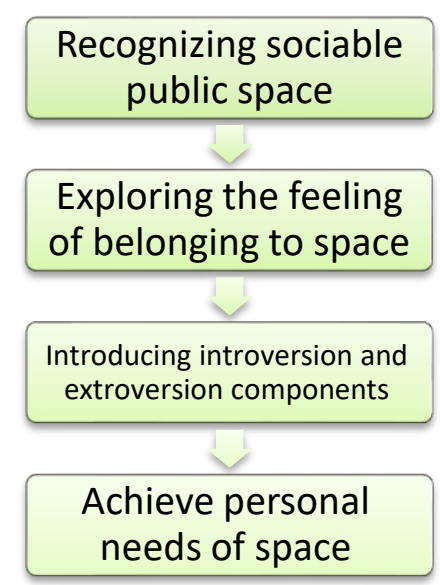

Figure 1: Research process in the above research. Source: Authors. 


\section{Sociable public space}

Public space can be defined as a space that allows people to access it. The activity takes place in the public space and is controlled by the community. The public space is therefore managed "to meet the needs of the people and the interests of the community" (Madanipour, 2003).

The main function of the public space is to provide and provide for the presence of the people, so its social and cultural dimensions have a special place (RAfiian \& Khodai, 2009)Social and human components of public space should therefore be considered. Socialization has always been the need for public space, and the life of that space depends on human presence. Because without addressing the relationship between individuals one cannot expect "healthy community institutions, normative behaviors, and trust in one another"(Putnam, 1998). For this reason, the concept of socialization plays an important role in the public space of the city. The sociable public space leads to a higher quality of social interactions in the environment. It also helps people be present in the urban space and meet the "emotional and emotional" needs of individuals. (Shojaii \& Parto, 2014)

Sociable space always brings people together in the environment. Therefore, spaces that are in line with social and cultural habits and behaviors increase the sense of belonging. Because space is known more than social and cultural form (Pakzad, 2010)Therefore, attention to the sense of belonging created between the individual and the environment has an impact on the effectiveness of the architectural space. Thus, the components of sense of place, sense of place and place identity are factors that influence the performance of public space (RAfiian \& Khodai, 2009). The authors have created the following table to describe the concepts mentioned and express their views on the views of experts.

Table 1: Examines the concepts of socialization in the public space. Source: Authors.

\begin{tabular}{|l|l|l|l|}
\hline $\begin{array}{l}\text { Components needed } \\
\text { for a sociable public } \\
\text { space }\end{array}$ & References & $\begin{array}{l}\text { Requires the } \\
\text { realization of the } \\
\text { components }\end{array}$ & Social Outcome \\
\hline presence of people & $\begin{array}{l}\text { Madanipour 2000, } \\
\text { Rafieian 2009 }\end{array}$ & $\begin{array}{l}\text { Attention to social } \\
\text { and personality } \\
\text { concepts }\end{array}$ & $\begin{array}{l}\text { A sense of } \\
\text { belonging to space }\end{array}$ \\
\hline $\begin{array}{l}\text { Providing } \\
\text { psychological and } \\
\text { emotional need }\end{array}$ & $\begin{array}{l}\text { Partoei 2015, Pakzad } \\
2009\end{array}$ & $\begin{array}{l}\text { Strengthening Social } \\
\text { Relations }\end{array}$ & \\
\hline $\begin{array}{l}\text { Pay attention to mold } \\
\text { culture in the } \\
\text { environment }\end{array}$ & $\begin{array}{l}\text { Putnam 1998, } \\
\text { Rafiean 2008 }\end{array}$ & $\begin{array}{l}\text { Madani Pour 2000, } \\
\text { Pakzad 2010 }\end{array}$ & \\
\hline Activities in space & & \\
\hline
\end{tabular}

\section{Feelings of belonging}

The sense of belonging is one of the influential factors in urban space. Because this is the constituent component of the "spirit of place" in the city. The existence of such a component helps to make the city more human and evolve. People's sense of place can have different spatial and spatial effects. Also, the sense of place affects human mental health (Hegerty-Hazel, 
In addition, according to Sergeant (2002) the feeling of belonging to an environment avoids the "nostalgia" disease. The sense of belonging to a place is one of the facets of the sense of place; one's mental perception of the environment is more or less conscious. This emotional reaction between the person and the environment creates an intrinsic relationship between the person and space. This relationship is such that one's "understanding and feeling" aligns with the environment. This sense of interaction between the person and the environment creates the fact that space is intertwined with the "sensory and behavioral attributes" of individuals. This process enhances cultural components and social relationships in society and allows them to review memories and create social identities for individuals (Falahat, 2005) Consequently, social interaction is a necessity for responding to human needs for transplantation and a sense of belonging.

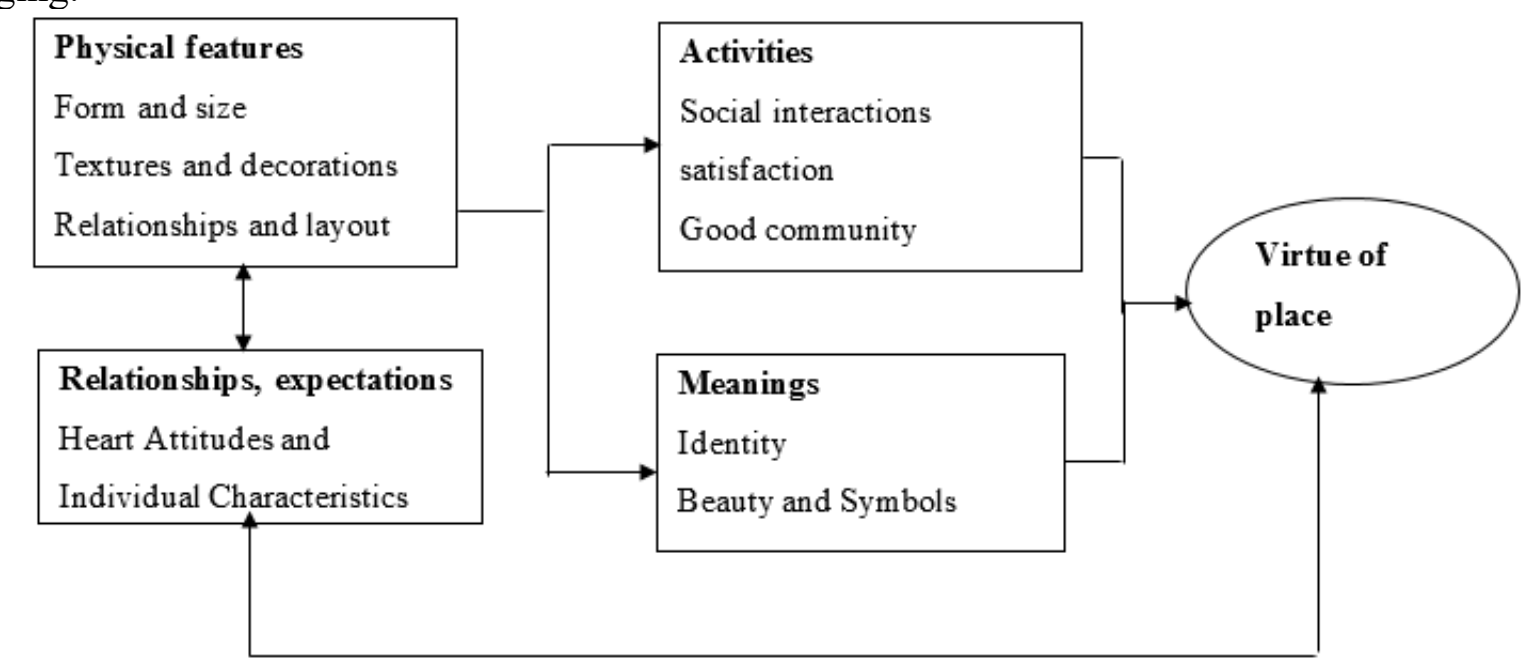

Figure 2: Factors Influencing the Sense of Place and Its Formation in Discretion 2005.

Source: Tavakkoli nia et al. 2015.

In describing and analyzing how to create a sense of belonging to the place, one must pay attention to "individual and collective values" in the environment. Therefore, the social and individual behavior of individuals in the environment originates from this importance .(Lee \& Canter, 1971) In psychology, too, the sense of belonging is regarded as a relationship between the individual and a particular environment, and from an identity point of view, it is the relationship between the individual and the social environment that constitutes the identity of the individual and the environment. In fact, the sense of belonging to a place encompasses a shared feeling, emotion and culture between the individual and the environment. Thus belonging to the place will be in addition to the intrinsic and personal notions of culture in a society(Low \& Altman, 1992). The sense of belonging in architecture is the result of the three factors of the individual, social interaction and the environment. On the one hand, a sense of belonging to a place is involved with one's characteristics, and on the other hand, social relationships and relationships with others in the environment affect the sense of belonging. (Javan Foroozandeh \& Motalebi, 2012) It can also be said that the affecting components of a sense of belonging are derived from "the individual and his or her surroundings". Therefore, components such as "environmental factors" and "individual factors" will create a sense of belonging in the architectural space (Tavakolinia, Afrasiabi rad, \& Bochani, 2015)Finally, the authors categorize the above concepts into diagrams to illustrate the path to attaining a sense of belonging to the environment through expert opinion. 


\section{(10) TECHNIUM}

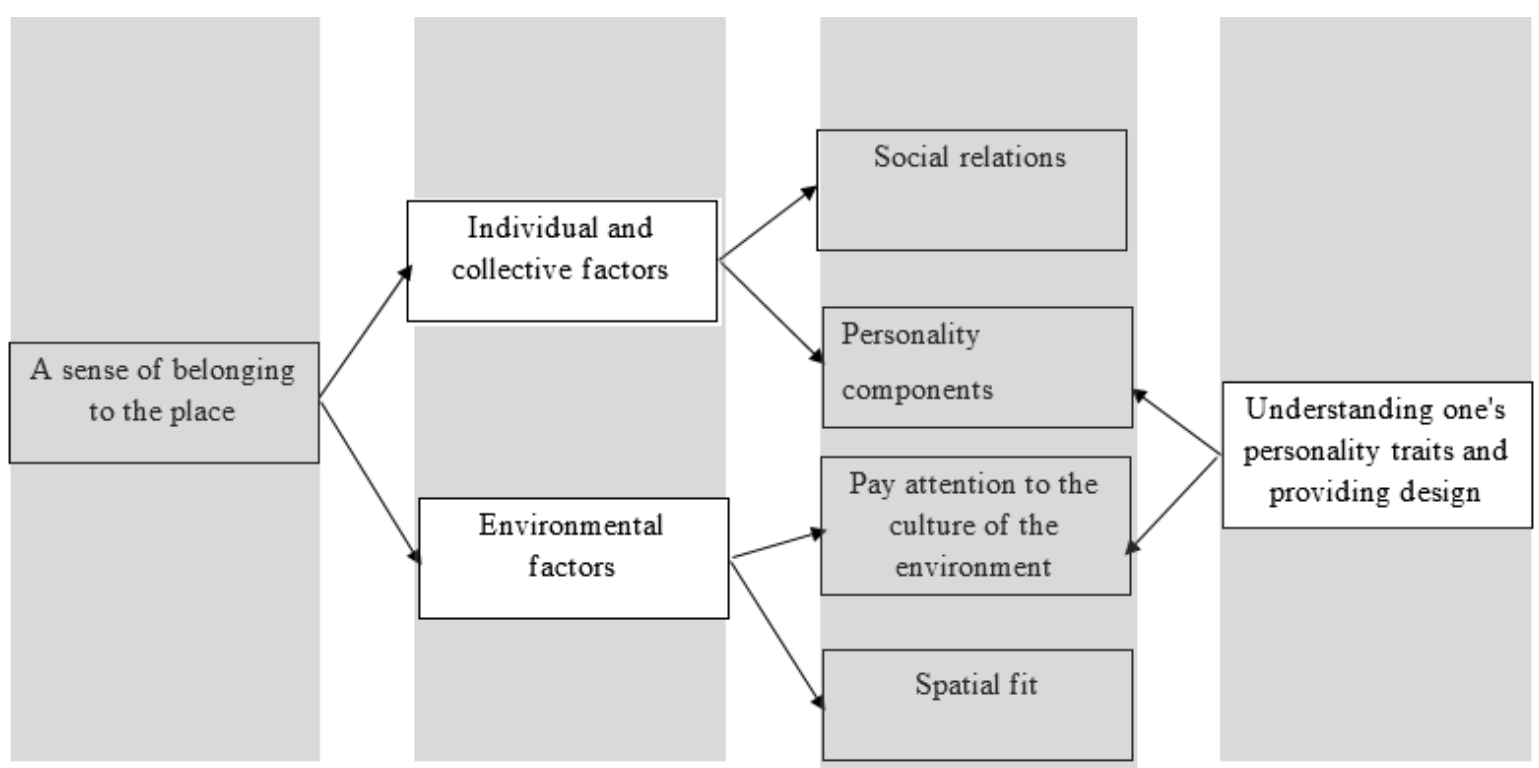

Figure 3: Classification of the concepts of emotion Source: Authors.

\section{Introversion and Extraversion}

As mentioned above, personality concepts influence the quality of the environment. Therefore, identifying and paying attention to the needs of individuals should be investigated. Therefore, psychosocial factors play a role in people's perception of the environment (Ezati \& Abbasi, 2013) .One of the most important components of these factors is human personality. Because human beings Unwanted Adapts his personality to the environment. (Saghafi \& Tageri Saiah, 2017) The impact of personal differences on personal space is unthinkable. These differences can range from personality differences to personality disorders. For example, an introvert takes more personal space than an extrovert and spends more time bouncing off his invisible bubble. Similarly, those who are prone to anxiety are more likely to distance themselves and others.(Altman, 1975)Also, people who are more self-confident or need more connection with others have shown that they need less personal space.(Bell, Esses, \& Maio, 1996) Factors such as personality and individual behavior make a person psychologically unique. Carl Jung introduced a dual classification based on extraversion and introversion, which is part of everyday human activities. Extroverts live according to external needs and introverts emphasize their mental values.(Namazian \& Mehdipour, 2013)

\section{Introversion and Extraversion Properties}

Yung believed that factors such as introversion and extroversion interact with one another, He also believed that these two factors derive from the types of innate and innate characteristics that can grow and evolve in life (Ross, 1997) .In fact, each person communicates with one of these two factors to the world. Usually the introverted person's main orientation is inward and outward (Pervin \& John, 1999) Therefore, the introvert is aware of her inner thoughts and feelings and is affected by this. This does not mean, however, that the introvert does not see or understand the outside world, but the intrinsic factors have a greater influence on his or her mind(Karimi, 2005). In a simpler sense, introverts interact more with their thoughts and emotions at the moment than with the relationships around them, Also, what they respond to is different from what they have in existence. In addition, the introvert is "thoughtful, thoughtful, and cautious." But the extroverted person tends to the outside world and is socially "engaged, active, and courageous." Also one of the main features 
of extroversion is the attention to external consonants, which means that the extroversion is stimulated by external factors. He then adjusts his thoughts and feelings to the environment and does not influence himself. (Same) Eisenk's view of introverts is more stimulated by extroversion than by extroverts because of their relevance to extroverts, and with a great deal of attention to emotional implications, but unlike extroversion, they have low tolerance thresholds. These behaviors are related to the human brain. He finds that introverted brains are more susceptible to introverts, whose differences are genetic based (Schultz \& Schultz, 2007)

\section{Extraversion}

Extroverts are energized by being with others, interested in talking and exchanging ideas. They also want to be the focus of attention. Extravagansin social relations always place their focus on the outside world. In order to learn better about scientific work, they need to discuss. As a result, they are easier to recognize and express their emotions more easily (Paul, Barbara, \& Kang, 1999)

\section{Introverts}

Introverts are energized to spend time for themselves and enjoy solitude and silence. They also do not want to be ignored. Introverts put their focus on their inner world. In addition, they deal with their thoughts in every environment. Better introspective learning is practiced and meditated. As a result, they keep their passion for themselves and act more privately and their personal information is less updated, in the following table, the authors classify introverted and extroverted personality traits.(Paul et al., 1999)

Table 2: Introversion and extroversion personality traits Source: Authors.

Introverts

They enjoy being with themselves

Getaway from society

They don't pay attention to environmental stimuli

They find themselves in an environment of self-harming thoughts

Emotions from the environment are less likely to occur

\section{Extroverts}

Interested in social communication

Needs attention

Sensitivity to environmental stimuli and surrounding events

Varietful

Say easily information about their inner world

\section{Personality Components in Architectural Space}

The life of the architectural space always requires a human being who creates vitality and vitality by presenting himself with daily activities. (AZIZI, 2006)Therefore, an environment should satisfy users of space so that people are interested in space and feel a sense of belonging to the environment. Also consider themselves out of space or in other words feel "childish"(Abolah Zade, Arzhmand, \& Pour Ahmad, 2017). That's why it's important to create a person-centered environment. As mentioned above, introverts and extroverts also have interactions. Therefore, the designers who applied these concepts to their designs used contrasting properties in their form. Socialization and socialization are both human needs(Altman, 1975). But flexible environments meet both needs, meaning that the environment can have both "collector" and "scatterer" features. Private space is protected as long as we need to interact with others and when we do not wish to do so (Shahcheragi \& Bandarabad, 2015)One can also point to Park Guell in Barcelona, where Gaudí has artfully created socialization and socialism. So people can sit in groups in concave areas and talk 
about socialization properties in space or in convex areas, individually and in relative isolation. And they might study or just watch the scene around them. Which represents an escapist community.(Lawson, 2007)

Figure 4: Image of convex and concave spaces in the Park Guell Barcelona Source:
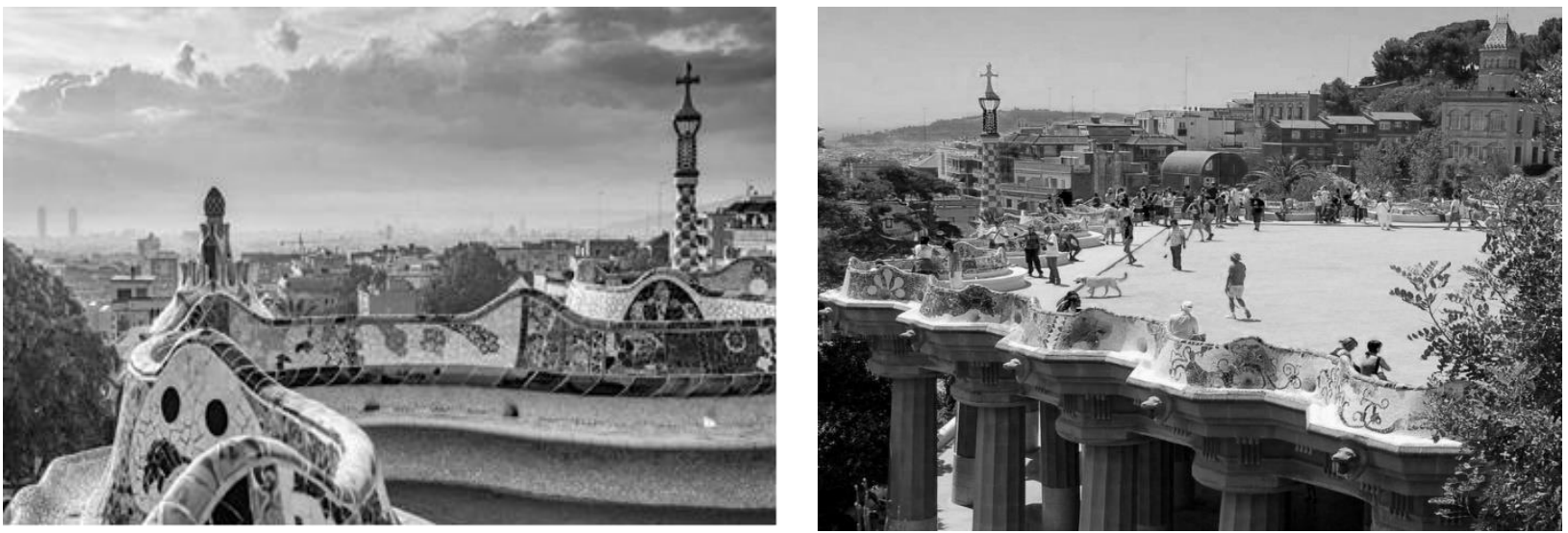

https://www.barcelonahacks.com

\section{Component analysis of personality traits}

The need for privacy and privacy in the architectural space is a must. Because space users tend to spend hours separating from the crowd. This decision is based on his personality and needs(Pakzad, 2010). Course, depending on the opinions of experts on the needs of individuals, it can be said that introverts are more interested in staying away from crowding. And, on the other hand, extroverts are interested in being in vibrant spaces. This can happen outside of public spaces such as Google Park and be designed to have the same effect. For example: If members of a group are sitting face to face or in a row, A person who is centered, that is, sitting where others can see him directly, can have a greater influence on other people in the crowd. (Madanipour, 2003)It can be said that having a centrality in the architectural space to satisfy the extravagant need of space has a great impact. 
And also considering the distant parts of the crowd can attract introverts. In fact, space has to take both characters into account and find a solution. In the other part we can mention the diversity in space; Extraterrestrials tend to have a space in which they have undiscovered areas to constantly operate in those spaces. But introverts prefer to work in a
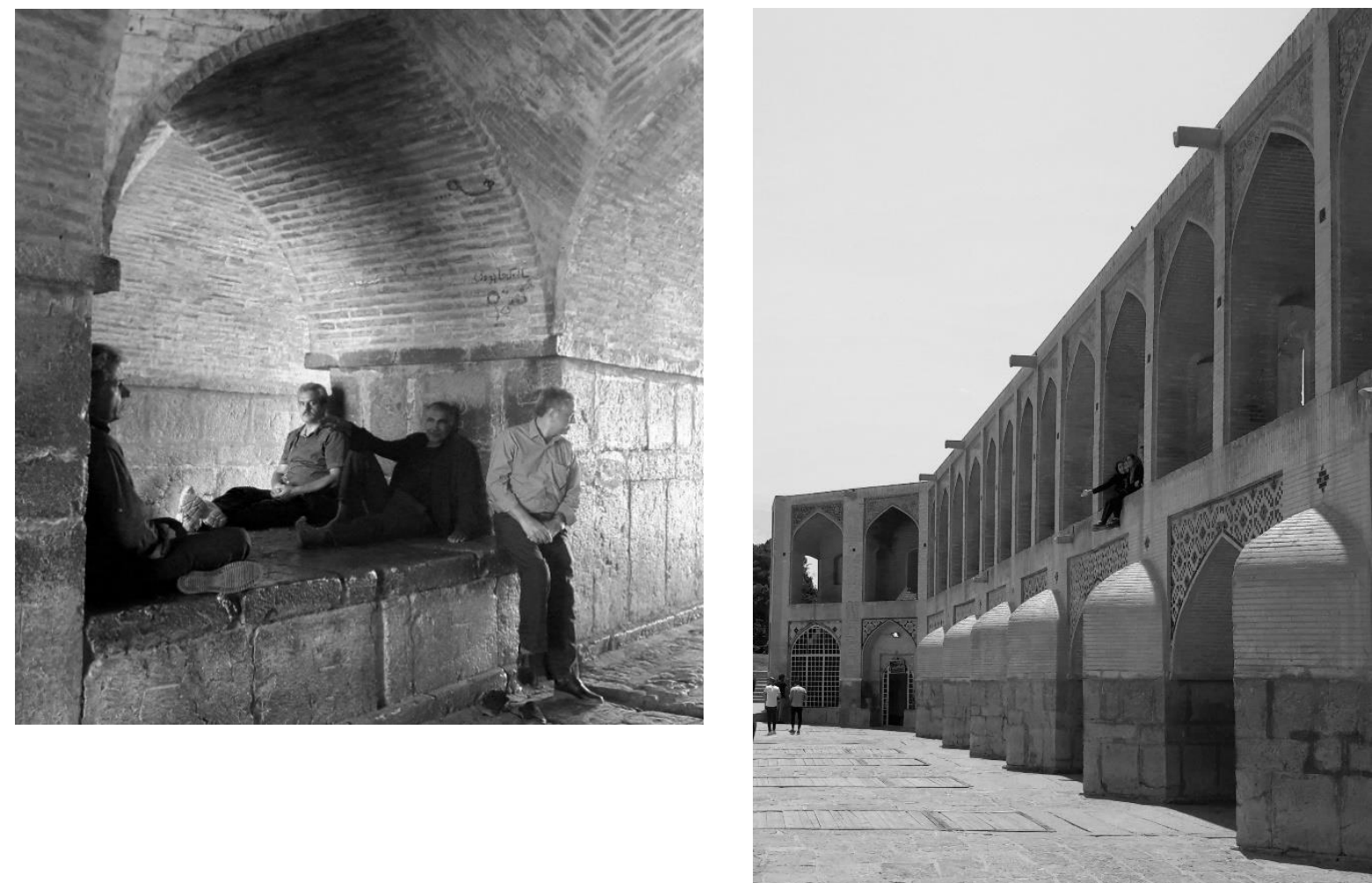

well-known space of high spatial quality. Extraterrestrials always need attention and vision, so the space that gives them the opportunity is attractive to them. On the other hand, introverts also suffer from being exposed and controlled by other people, seeking a stress-free environment. In extraverted individuals, energy and emotion must be discharged objectively and instantaneously so space must be able to discharge energy without damaging itself or space. However, introverts are excluded from the rule because of their internal emotions. These concepts can be easily seen in the Khaju Bridge. People singing under the bridge to vent their emotions and express their innate needs, and people who spend time in the shadows of the bridge enjoying the space and the landscape.

According to Kopeck (2006) components such as individual personality, sociological and human societies are effective in personality development. Also, those components pave the way for environmental growth. Thus the development of the human personality is related to the growth of the environment. Organic theory states that: Factors such as environmental factors in combination with human factors lead to specific behaviors(Shahcheragi \& Bandarabad, 2015). Therefore, a person behaves in a certain manner appropriate to his or her culture and personality. These behaviors do not meet the needs of individuals and are derived from personality components such as introversion and extroversion. The authors in the following table try to categorize the need for introverts and extroverts from space. This classification is based on personality descriptions expressed by experts. 
Table 3 Personality Needs of Extraverts and Extraverts from Space Source: Authors.

Introverts

\section{Existence of privacy in space}

A space for long-term use

Relax in the environment

Having the right perspective for yourself

\section{Extroverts}

Space to present yourself

Several diverse spaces

A space for group activities

Space scale for energy discharge

\section{Conclusion}

As a result of examining the personality needs in the socialization of public space, it can be argued that an appropriate public space with this approach requires space for energy depletion, space, diversity in the environment, and high quality of space for long-term use. Space tranquility and space for group activities are also essential to create socialization in the public space. Taking space between spaces and creating space for social interaction in the environment also affects the quality of socialization and people's use of space.

In this study, according to the opinions of scholars and researchers in the field of psychology and architecture, factors regarding introverted and extroverted individuals have been extracted. In fact, introversion and extroversion are two components of personality in which individuals meet their needs from space. Paying attention to these needs and behaviors leads to a sense of interest in the environment and makes one feel connected to the space. Because one has memories of the environment and sees their identity in those memories and their past. Therefore, dealing with personality components is one of the factors that creates a sense of belonging to space. The present study has always sought to elucidate the factors that create a sense of belonging in space. Therefore, one of the factors that create a sense of belonging is a space that is shaped by personal needs.

However, it should be said that in any architectural space the components that are appropriate for each character can be annoying to the other. For this reason, both components must be dealt with in the public sphere, and both components must be considered so as not to harm the other.

\section{References}

[1] Abolah Zade, S. M., Arzhmand, M., \& Pour Ahmad, A. (2017). Dimensions of Social Sustainability in Traditional Iranian Neighborhoods, Case Study: Sangi Siah Neighborhood, Shiraz. Architecture and Urban Development Arman Shar, 10.

[2] Altman, I. (1975). The Environment and Social Behavior: Privacy, Personal Space, Territory, and Crowding.

[3] AZIZI, M. M. (2006). Sustainable Residential Neighborhood: The Case Study of Narmak Neighborhood, Tehran. 3.

[4] Bell, D. W., Esses, V. M., \& Maio, G. R. (1996). The utility of open-ended measures to assess intergroup ambivalence. Canadian Journal of Behavioural Science/Revue canadienne des sciences du comportement, 28(1), 12.

[5] Carmona, M., Heath, T., Oc, T., \& Tiesdell, S. (2012). Public places-Urban spaces (m. A. Shokohi, Zahra. Salehi, Esmail, Trans.): Tehran, University of Art, 2012.

[6] Ezati, M., \& Abbasi, H. (2013). Aesthetics in Architecture, International Conference on Civil Engineering, Architecture and Sustainable Development. Islamic Azad University of Tabriz.

[7] Falahat, M. H. (2005). The concept of place sense and its constituent factors. Honar hay ziba, university of Tehran, 26. 
[8] Forgas, J. P., \& Jones, R. (2000). Interpersonal behaviour: The psychology of social interaction (M. Firoozbakht \& K. Beygi, Trans.): Tehran: Abjad.

[9] Gehl, J. (2011). Life between buildings: using public space (A. K. Ghafari, Freshteh. Mehrabi, Nastaran, Trans. Z. Varesi Ed.): Tehran, Parham Naqsh.

[10] Gehl, J., \& Gemzøe, L. (2004). Public spaces-public life.

[11] Golany, G. S., \& Ojima, T. (1996). Geo-space urban design: John Wiley \& Sons.

[12] Hegerty-Hazel, E. (1991). Science specific factors for women and men who discontinue first year university studies in science and engineering. Paper presented at the Action for Equity: The Second Decade. The Sixth International GASAT Conference.

[13] Javan Foroozandeh, A., \& Motalebi, G. (2012). The concept of sense of place and its constituents. Hoviat shahr Journal, 5(8), 27-37.

[14] Karimi, Y. (2005). Personality Psychology. Tehran: Payam noor University Publication., 14.

[15] Lawson, B. (2007). Language of space (A. K. Eynifar, Foud, Trans.): Routledge.

[16] Lee, L. L., \& Canter, S. M. (1971). Developmental sentence scoring: A clinical procedure for estimating syntactic development in children's spontaneous speech. Journal of Speech and Hearing Disorders, 36(3), 315-340.

[17] Low, S. M., \& Altman, I. (1992). Place attachment. In Place attachment (pp. 1-12): Springer.

[18] Madanipour, A. (2003). Public and private spaces of the city (F. Norian, Trans.): Routledge.

[19] Namazian, A., \& Mehdipour, A. (2013). Psychological demands of the built environment, privacy, personal space and territory in architecture. International Journal of Psychology and Behavioral Sciences, 3(4), 109-113.

[20] Pakzad, J. (2010). Qualitative Measures of Space Measurement. Abadi, 3.

[21] Paul, D., Barbara, B., \& Kang, J. (1999). The art of speed reading people: how to size people up and speak their language. place unknown]: Little, Brown and Company.

[22] Pervin, L. A., \& John, O. P. (1999). Handbook of personality: Theory and research (M. J. J. a. P. Kadivar, Trans.): Elsevier.

[23] Putnam, R. D. (1998). Social capital: Its importance to housing and community development-Foreword. In: FANNIE MAE FOUNDATION 4000 WISCONSIN AVE, NW, NORTH TOWER, STE ONE ....

[24] RAfiian, M., \& Khodai, Z. (2009). Investigation of Indicators and Criteria Affecting Citizens' Satisfaction with Urban Public Spaces. Strategic Journal, 21.

[25] Ross, A. (1997). Personality psychology theories and processes. Tehran: Ravan, 6769.

[26] Saghafi, M. J., \& Tageri Saiah, F. (2017). Architecture and MBTI; Investigation of How the Use of The Characterology and Personality Type of the Space User in Housing Design. Honar hay ziba, university of Tehran, 22(1), 75-88.

[27] Schultz, D. P., \& Schultz, S. E. (2007). Personality theories. Tehran: Virayesh Publication, 11.

[28] Shahcheragi, A., \& Bandarabad, A. (2015). Environed in Environment.

[29] Shojaii, d., \& Parto, P. (2014). Factors Influencing the Creation and Promotion of Socialization in Public Spaces of Different Scales in Tehran (Case Study: Public Spaces of Two Neighborhoods and One District in Tehran District 7). . Bagh Nazar Scientific Research, 12(34), 93-108. 
[30] Tavakolinia, J., Afrasiabi rad, M. S., \& Bochani, M. h. (2015). Measurement of Spatial Feelings and its Spatial-Spatial Effects in Urban Decay Textures (Case Study: Sahel Abad Neighborhood, Shiraz). . Zagros Landscape Geography and Urban Planning, 25(7).

[31] Thomson, D. E., \& Etienne, H. (2017). Fiscal crisis and community development: The great recession, support networks, and community development corporation capacity. Housing Policy Debate, 27(1), 137-165.

[32] Tibbalds, F. (1992). Making people-frendly towns. Improving the public environment in towns and cities Spon Press, London, 2. 